\title{
MODEL GERAKAN DAKWAH DI INDONESIA
}

\author{
(Studi Kasus Pada Dakwah Muhammadiyah)
}

\author{
Nahdatunnisa Asry
}

\begin{abstract}
Da'wah is the delivery of Islamic teachings can be in the form of amar makruf and nahi munkar. The pattern of da'wah can take the form of cultural propaganda, political preaching, and economic da'wah. Efforts to implement or ground social monotheism supported by four doctrines also live in Muhammadiyah circles. The doctrine is the doctrine of enlightenment of the people, the doctrine of encouraging pious charity, the doctrine of cooperation for virtue, the doctrine of not practicing politics. Da'wah is not understood as a tabligh, but a massive movement on various aspects of human life. Muhammadiyah balances the spirituality of da'wah with social charity as a real movement in response to the problems of the ummah at various levels.
\end{abstract}

Keyword: Da'wah, Muhammadiyah, Case Study.

\section{Pendahuluan}

Islam merupakan agama yang berisi petunjuk-petunjuk agar manusia secara individual menjadi manusia yang baik, beradab, dan berkualitas. Di samping itu Islam sebagai agama dakwah dari bahasa arab yang asal katanya

artinya menyeru, mengajak, memanggil, menjamu. Maksudnya adalah agama yang disebarluaskan secara damai, tidak lewat kekerasan. Dakwah memiliki tiga unsur pengertian pokok yaitu :

1. Dakwah adalah proses penyampaian agama Islam dari seseorang kepada orang lain.

2. Dakwah adalah penyampain ajaran Islam tersebut dapat berupa amar makruf (ajaran kepada kebaikan) dan nahi munkar (mencegah kemungkaran).

3. Usaha tersebut dilakukan secara dasar dengan tujuan terbentuknya suatu individu atau masyarakat yang taat dan mengamalkan sepenuhnya ajaran Islam. 
Dengan pengertian dakwah di atas, pola dakwah dapat mengambil bentuk antara lain dakwah kultural, dakwah politik, dan dakwah ekonomi. Dakwah kultural adalah aktivitas dakwah yang menekankan pendekatan Islam kultural yaitu pendekatan yang berusaha meninjau kembali kaitan doktrinal yang formal antara Islam dan politik atau Islam dan negara. Dakwah politik adalah gerakan dakwah yang ada di dalam atau ada pada kekuasaan. Dakwah ekonomi adalah upaya mewujudkan dalam realitas kehidupan umat Islam, ajaran-ajaran Islam tertentu yang dapat berfungsi untuk meningkatkan sosial ekonomi umat.

Kunci dari defenisi dakwah adalah panggilan atau ajakan kembali ke jalan Allah karena hakikat dakwah adalah memanggil atau mengajak kembali manusia kepada agama. Hal ini karena pada hakikatnya semua manusia dilahirkan dengan keadaan bertuhan atau beragama. Manusia adalah makhluk religius. Jadi, tugas dakwah adalah memanggil atau mengajak manusia agar kembali kepada apa yang pernah diucapkan ketika masih berada di dalam ruh yaitu beriman kepada Allah.

Munculnya gerakan dakwah keagamaan ala Muhammadiyah di atas panggung sejarah keagamaan Islam di Indonesia sebenarnya merupakan peristiwa sosial-budaya biasa, yakni peristiwa sosial-budaya bernapaskan keagamaan Islam, yang merupakan “eksperimen sejarah” yang cukup spektakuler, khususnya untuk ukuran saat itu.

Tantangan zaman yang menghimpit umat Islam saat berdirinya Muhammadiyah pada 1912 dapat disebutkan antara lain: umat Islam-hampir di seluruh dunia-berada di bawah belenggu cengkraman penjajahan, kebekuan pemikiran keagamaan, rendahnya mutu pendidikan umum yang diselenggarakan oleh pemerintah kolonial Hindia Belanda dan yayasan-yayasan Katolik dan Protestan. Hal ini tidak saja menyangkut pendidikan, tetapi juga dalam pelayanan sosial, seperti rumah sakit, panti asuhan, rumah jompo, dan lain sebagainya. Belum lagi menyebut situasi umu umat Islam yang sangat mudah dijumpai di sana-sini seperti kebodhan, keterbelakangan, dan kemiskinan. 
Dalam situasi yang menghimpit seperti itu, muncullah gagasan untuk membentuk suatu "persyarikatan" (organisasi) keagamaan yang berupaya sebisabisanya merespons tantangan zaman tersebut. Usaha umat Islam untuk merespons tantangan zaman dan diwujudkan dalam bentuk pendirian sebuah "organisasi"-di lingkungan Muhammadiyah lebih di kenal dengan istilah "persyarikatan"-adalah ciri khas model gerakan pembaruan keagamaan di Indonesia. ${ }^{1}$

Film Sang Pencerah karya Hanung Bramantyo secara sederhana menggambarkan corak gerakan dakwah yang dilakukan persyarikatan Muhammadiyah. Substansi gerakannya jelas. Ia ingin membersihkan praktik keagamaan dari unsur lain yang kerap menggeser kemurnian ajaran dari sumber utamanya Al-Qur'an, dan As-Sunnah. Misalnya, setting ketika Ahmad Dahlan muda mendobrak tradisi dan meluruskan arah kiblat yang telah lama melekat dalam praktik keagamaan masyarakat kampung Kauman Yogyakarta. Meski sedikit mengundang kesan telah mengungkap luka lama yang pernah melilit hubungan intern umat Islam, film itu tetap menjadi representasi gerakan dakwah yang diperankan para pendahulu organisasi Muhammadiyah.

Hingga saat ini, corak gerakan dakwah itu tetap tidak berubah. Benang merahnya terlihat jelas. Orientasi dakwah Muhammadiyah merupakan implementasi gerakan pembaruan dalam pengertian pemurnian (purification) ajaran Islam. Oleh karena itu organisasi ini kemudian dikategorikan sebagai wujud formal gerakan pembaruan yang mulai muncul dengan masuknya abad ke $-20 .^{2}$

\section{PEMBAHASAN}

\footnotetext{
${ }^{1}$ M. Amin Abdullah, Intelektualisme Muhammadiyah: Menyongsong Era Baru Pendekatan “Teologis” Dalam Memahami Muhammadiyah. (Bandung: Mizan, 1995) h. 7.

${ }^{2}$ Asep S. Muhtadi. Meretas Jalan Dakwah: Benang Merah Gerakan Ormas Islam (Dakwah dan Gerakan Pembaruan Muhammadiyah)(Bandung: MUI Kota Bandung, 2012), h.45.
} 
Muhammadiyah sebagai gerakan dan dakwah, sudah menjadi pemahaman umum di kalangan masyarakat, baik di dalam atau di luar Muhammadiyah. Muhammadiyah sendiri pun menyadarinya, bahwa predikat tersebut bukanlah merupakan asumsi yang salah. Sebab motif utama pendirian Muhammadiyah -oleh para pendirinya, yang dipelopori oleh KH. Ahmad Dahlan-adalah untuk menjadi instrumen penting untuk pelaksanaan dakwah islamiyah secara menyeluruh. Namun apa yang dilakukan dengan dakwah Muhammadiyah bukan dakwah dalam arti sempit. Gerakan dakwah yang dilakukan bersifat multi wajah, sebagaimana halnya Islam yang mengatur berbagai aspek kehidupan manusia

\section{A. Doktrin Dakwah Muhammadiyah}

Membahas doktrin berarti membahas tentang normativitas sesuatu. Secara tekstual, dakwah sering diartikan dengan mana: "mengajak" dengan beberapa derivasi maknanya. Bagi Muhammadiyah, dakwah itu memerlukan sarana dan prasarana. Andaikata dakwah itu dimaknai sebagaimana dalam QS/16:125,

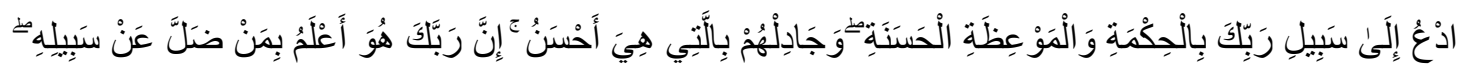

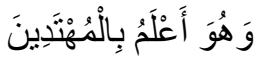

"Serulah (manusia) kepada jalan Tuhan-mu dengan hikmah dan pelajaran yang baik dan bantahlah mereka dengan cara yang baik. Sesungguhnya Tuhanmu dialah yang lebih mengetahui tentang siapa yang tersesat dari jalan-Nya dan dialah yang lebih mengetahui orang-orang yang mendapat petunjuk".

maka QS. Ali Imran/3:104 dapat dimaknai bahwa "dakwah" adalah serangkaian kegiatan manajerial "pengislaman" yang dikerjakan secara sistemik, dengan serangkaian perencanaan, pengorganisasian, pelaksanaan, dan pengawasan yang matang dan dapat dipertanggungjawabkan. 
Dakwah sebagai salah satu komponen penting dari tindakan manusia sebagai khalifah haruslah dikemas sedemikian rupa sehingga dapat menawarkan sesuatu yang berarti bagi umat manusia dalam rnagka menjadikan dirinya sebagai hamba dan khalifah Allah secara ideal. Idealitas tersebut bisa dijelaskan dengan beberapa ayat al-Qur'an yang secara eksplisit maupun implisit menawarkan gagasan ideal tentang: input, proses, dan output yang diharapkan Allah dalam wilayah personal, interpersonal dan sosial, karenanya, proses dakwah di muhammadiyah merupakan serangkaian aktivitas manusia yang diorganisasikan dalam berbagai sektor sehingga melahirkan sebuah gerakan nyata dan dirasakan oleh masyarakat luas.

Dalam wilayah personal, Allah memperkenalkan gagasan "taqwa", yang ketika sifat itu melekat pada pribadi-pribadi manusia, maka akan lahirlah hamba-hamba dan khalifah-khalifah ideal; dalam wilayah interpersonal Allah menawarkan gagasan "ukhuwwah", yang ketika sikap itu dimiki oleh setiap orang dalam relasi interpersonalnya, maka akan lahir hubungan interpersonal yang ideal; dalam wilayah sosial Allah menjelaskan gagasan "ummatan wahidah", sebagai produk ideal dari kesadaran untuk bertakwa pada diri manusia dan berukhuwwah pada diri manusia dalam relasi interpersonalnya.

Kesalehan personal (ketakwaan) dalam Muhammadiyah harus dibuktikan denga keshalehan sosial. Hal inilah yang mendasari sebelum berdirinya pimpinan Muhammadiyah di tingkat bawah (seperti Cabang dan Ranting) disyaratkan sebelumnya harus memilki mal sosial, baik itu majlis ta'lim, sekolah, panti asuhan, tempat kesehatan dan lain sebagainya. Dengan demikian adapula yang disebut doktrin tauhid sosial dalam Muhammadiyah.

\section{Doktrin Tauhid Sosial}

Salah satu peran dakwah Muhammadiyah sejak awal kelahirannya tidak lepas dari ketegasannya dalam meluruskan aqidah umat Islam yang pada saat itu banyak tercampuri oleh ajaran budaya lain yang dianggap bagian dari Islam, dahlan mencoba 
menyampaikan risalah kebenaran ajaran Islam melalui jalur pemurnian ajaran Islam dengan mengembalikan kepada sumber otentiknya yaitu Al Qur'an dan Sunnah.

Namun, melewati ajaran tauhid yang bersifat personal, Muhammadiyah juga melakukan doktrin tauhid yang bersifat sosial. Sebagai gerakan dakwah, Muhammadiyah tidak hanya menyadarkan umat dari aspek personal tetapi juga membangun kesadaran tauhid sosial sebagai basis dan komitmen dakwahnya.

Di dalam perjalanannya upaya untuk mengimplementasikan atau membumikan tauhid sosial didukung oleh empat doktrin lainnya yang juga hidup di kalangan warga Muhammadiyah. Empat doktrin tersebut adalah:

\section{Doktrin Pencerahan Umat}

Para tokoh Muhammadiyah pendahulu tidak pernah bosan meningatkan masyarakat Islam Indonesisa bahwa ilmu pengetahuan aadalah barnag kaum muslimin yang hilang yang harus direbut kembali. Itulah sebabnya, pada tahap awal pertumbuhannya Muhammadiyah tidak langsung membangun kongsi-kongsi dagang tetapi membangun sekolah sebanyak mungkin. Pertimbangannya jelas yakni kebodohan telah menjadi musuh terbesar umat Islam dan mustahil dapat membangun masa depan yang lebih baik bilamana kebodohan dan keterbelakangan tetap saja melekat lengket dalam kehidupan mereka.

Lewat doktrin enlightment bagi umat Islam Muhammadiyah merintis sekolah umum sebanyak-banyaknya. Bagi Muhammadiyah, kitab kuning dan kitab putih sama pentingnya. Anjuran tokoh-tokoh Muhammadiyah agar ZIS (Zakat, Infaq dan Shadaqah) tidak saja disalurkan ke mesjid, tetapi kalau perlu lebih banyak lagi yang disalurkan ke lembaga-lembaga pendidikan. Alasannya, yakni umat Islam yang banyak memadati masjid tidak akan pernah 
dapat berangkat jauh bila mereka tetap terbelenggu dalam kebodohan dan keterbelakangan.

2. Doktrin Menggembirakan Amal Salih

Doktrin "iman tanpa amal salih" bagaikan "pohon tanpa buah" sangat dipegang oleh seluruh warga Muhammadiyah. Dalam benak warga Muhammadiyah, fungsi organisasi antara lain adalah untuk memobilisasi atau dalam bahasa Muhammadiyah untuk menggembirakan amal salih kolektif

Dilihat dari perspektif ini, lahirnya muhammadiyah merupakan terobosan besar. Sebelum muhammadiyah lahir, umat Islam sudah terbiasa menggerakkan amal salih dalam berbagai bidang kehidupan, akan tetapi hanaya bersifat kecil-kecilan di atas inisiatif individual belaka. Setelah Muhammadiyah lahir, kemampuan dan semangat beramal dari berbagai individu muslim dipadukan lewat sebuah organisasi.

3. Doktrin kerjasama untuk kebajikan

"Bekerjasamalah dalam kebaikan dan taqwa dan jangan bekerjasama dalam dosa dan permusuhan" (QS. Al-Maidah/5:2).

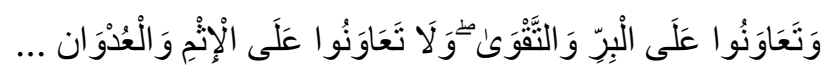

Ayat tersebut telah dijadikan doktrin dalam perjuangan Muhammadiyah. Sebagai organisasi dakwah yang berusaha mengajak seluruh lapisan masyarakat untuk menegakkan kebajikan dan mencegah kemungkaran, Muhammadiyah menghimbau para muballighin dan muballighat-nya untuk selalu dapat bekerjasama dengan semua pihak demi tercapainya tujuan baik bersama. Di kalangan para da'i Muhammadiyah ada semacam slogan hanya dengan iblis Muhammadiyah tidak dapat bekerjasama.

4. Doktrin tidak berpolitik praktis 
Dalam mencapai cita-cita perjuangannya untuk membangun masyarakat yang diridhoi Allah Swt., Muhammadiyah menghindari kegiatan politik praktis. Hal ini dikarenakan Muhammadiyah dalam membangun masyarakatnya bersifat jangka panjang. Muhammadiyah tidak ingin mengambil short-cut atau jalan pintas politik dengan membangun kekuasaan dan berambisi ikut berebut kekuasaan dengan kekuatan-kekuatan politik yang ada.

Logika Muhammadiyah adalah dengan membina masyarakat lewat siraman nilai-nilai Islam, Muhammadiyah berarti telah ikut mempersiapkan manusia-manusia yang berakhlak, memegang nilai-nilai dan norma-norma moral secara kuat, sehingga tatkala manusia-manusia tersebut masuk ke gelanggang politik praktis, mereka tidak akan menjadi homo politikus yang mengejar kekuasaan demi kekuasaan semata. ${ }^{3}$

\section{B. Ciri Gerakan Dakwah Muhammadiyah}

Dakwah Muhammadiyah tidak semata persoalan spiritual, tetapi juga sosial. Dakwah tidak dipahami sebagai tabligh, tetapi gerakan massif pada berbagai aspek kehidupan manusia. Muhammadiyah menyeimbangkan dakwah yang sifatnya spiritualitas dengan amal sosial sebagai gerakan nyata sebagai jawaban atas problem umat di berbagai levelnya.

Oleh karena, muhammadiyah memahami kata "dakwah" bukan sekadar melaksanakan kegiatan pengislaman dalam arti formal. Lebih jauh dari itu, dakwah bagi Muhammadiyah diartikan sebagai upaya penyeluruh untuk menumbuhkembangkan kondisi ideal dalam takaran "Islam". Sehingga rumusan tujuan Muhammadiyah selalu mengarah pada "pengislaman" dalam arti yang sebenar-benarnya (Islam dalam pengertian esensialnya).

${ }^{3}$ Roni Tabroni. Meretas Jalan Dakwah: Benang Merah Gerakan Ormas Islam (Revitalisasi Gerakan Dakwah Muhammadiyah)(Bandung: MUI Kota Bandung, 2012), h. 230-233. 
Ciri-ciri perjuangan Muhammdiyah itu adalah sebagai berikut:

\section{Muhammadiyah Sebagai Gerakan Islam}

Persyarikatan Muhammadiyah dibangun oleh KH Ahmad Dahlan sebagai hasil kongkrit dari telaah dan pendalaman (tadabbur) terhadap Alquranul Karim. Faktor inilah yang sebenarnya paling utama yang mendorong berdirinya Muhammadiyah, sedang faktor-faktor lainnya dapat dikatakan sebagai faktor penunjang atau faktor perangsang semata. Dengan ketelitiannya yang sangat memadai pada setiap mengkaji ayat-ayat Alquran, khususnya ketika menelaah surat Ali Imran, ayat:104, maka akhirnya dilahirkan amalan kongkret, yaitu lahirnya Persyarikatan Muhammadiyah. Kajian serupa ini telah dikembangkan sehingga dari hasil kajian ayat-ayat tersebut oleh KHR Hadjid dinamakan "Ajaran KH Ahmad Dahlan dengan kelompok 17, kelompok ayat-ayat Alquran", yang didalammya tergambar secara jelas asal-usul ruh, jiwa, nafas, semangat Muhammadiyah dalam pengabdiannya kepada Allah SWT.

Kelahiran Muhammadiyah itu tidak lain karena diilhami, dimotivasi, dan disemangati oleh ajaran-ajaran Al-Qur'an karena itu pula seluruh gerakannya tidak ada motif lain kecuali semata-mata untuk merealisasikan prinsip-prinsip ajaran Islam. Segala yang dilakukan Muhammadiyah, baik dalam bidang pendidikan dan pengajaran, kemasyarakatan, kerumahtanggaan, perekonomian, dan sebagainya tidak dapat dilepaskan dari usaha untuk mewujudkan dan melaksankan ajaran Islam. Tegasnya gerakan Muhammadiyah hendak berusaha untuk menampilkan wajah Islam dalam wujud yang riil, kongkret, dan nyata, yang dapat dihayati, dirasakan, dan dinikmati oleh umat sebagai rahmatan lil'alamin.

2. Muhammadiyah Adalah Gerakan Dakwah Islam Amar Ma'ruf Nahi Munkar 
Ciri kedua dari gerakan Muhammadiyah dikenal sebagai gerakan dakwah Islamiyah. Ciri yang kedua ini muncul sejak dari kelahirannya dan tetap melekat tidak terpisahkan dalam jati diri Muahammadiyah. Sebagaimana telah diuraikan dalam bagian sebelumnya bahwa faktor utama yang mendorong berdirinya Persyarikatan Muhammadiyah berasal dari pendalaman KHA Dahlan terdapat ayat-ayat Alquran Alkarim, terutama sekali surat Ali Imran, Ayat:104. Berdasarkan Surat Ali Imran, ayat : 104 inilah Muhammadiyah meletakkan khittah atau strategi dasar perjuangannya, yaitu dakwah (menyeru, mengajak) Islam, amar ma'ruf nahi munkar dengan masyarakat sebagai medan juangnya. Gerakan Muhammadiyah berkiprah di tengah-tengah masyarakat bangsa Indonesia dengan membangun berbagai ragam amal usaha yang benar-benar dapat menyentuh hajat orang banyak seperti berbagai ragam lembaga pendidikan sejak taman kanak-kanak hingga perguruan tinggi, membangun sekian banyak rumah sakit, panti-panti asuhan dan sebagainya. Semua amal usaha Muhammadiyah seperti itu tidak lain merupakan suatu manifestasi dakwah islamiyah. Semua amal usaha diadakan dengan niat dan tujuan tunggal, yaitu untuk dijadikan sarana dan wahana dakwah Islamiyah.

\section{Muhammadiyah Adalah Gerakan Tajdid}

Ciri ke tiga yang melekat pada Persyarikatan Muhammadiyah adalah sebagai Gerakan Tajdid atau Gerakan Reformasi. Muhammadiyah sejak semula menempatkan diri sebagai salah satu organisasi yang berkhidmat menyebarluaskan ajaran Agama Islam sebagaimana yang tercantum dalam Alquran dan Assunah, sekaligus membersihkan berbagai amalan umat yang terang-trangan menyimpang dari ajaran Islam, baik berupa khurafat, syirik, maupun bid'ah lewat gerakan dakwah. Muhammadiyah sebagai salah satu mata rantai dari gerakan tajdid yang diawali oleh ulama besar Ibnu Taimiyah sudah barang tentu ada kesamaaan nafas, yaitu memerangi secara total berbagai penyimpangan ajaran Islam seperti syirik, khurafat, 
bid'ah dan tajdid, sebab semua itu merupakan benalu yang dapat merusak akidah dan ibadah seseorang. Pemurnian tauhid dan ibadah tersebut, seperti:

$\checkmark$ Meniadakan kebiasaan menujuhbulani (Jawa: tingkeban), yaitu selamatan bagi orang yang hamil pertama kali memasuki bulan ke tujuh. Kebiasaan ini merupakan peninggalan dari adat-istiadat Jawa kuno, biasanya diadakan dengan membuat rujak dari kelapa muda yang belum berdaging yang dikenal dengan nama cengkir dicampur dengan berbagai bahan lain, seperti buah delima, buah jeruk, dan lain-lain. Masing-masing daerah berbeda-beda cara dan macam upacara tujuh bulanan ini, tetapi pada dasarnya berjiwa sama, yaitu dengan maksud mendoakan bagi keselamatan calon bayi yang masih berada dalam kandungan itu.

$\checkmark$ Menghilangkan tradisi keagamaan yang tumbuh dari kepercayaan Islam sendiri, seperti selamatan untuk menghormati Syekh Abdul Qadir Jaelani, Syekh Saman, dll yang dikenal dengan manakiban. Selain itu, terdapat pula kebiasaan membaca barzanji, yaitu suatu karya puisi serta syair-syair yang mengandung banyak pujaan kepada Nabi Muhammad Shallallahu 'alaihi wa sallam yang disalahartikan. Dalam acara-acara semacam ini, Muhammadiyah menilai, ada kecenderungan yang kuat untuk mengultusindividukan seorang wali atau nabi, sehingga hal itu dikhawatirkan dapat merusak kemurnian tauhid. Selain itu, ada juga acara yang disebut "khaul", atau yang lebih populer disebut khal, yaitu memperingati hari dan tanggal kematian seseorang setiap tahun sekali, dengan melakukan ziarah dan penghormatan secara besar-besaran terhadap arwah orangorang alim dengan upacara yang berlebih-lebihan. Acara seperti ini oleh Muhammadiyah juga dipandang dapat mengeruhkan tauhid.

$\checkmark$ Bacaan surat Yasin dan bermacam-macam zikir yang hanya khusus dibaca pada malam Jumat dan hari-hari tertentu adalah suatu bid'ah. Baginya ziarah hanya pada waktu-waktu tertentu dan pada kuburan tertentu, ibadah yang tidak ada 
dasarnya dalam agama, juga harus ditinggalkan. Yang boleh adalah ziarah kubur dengan tujuan untuk mengingat adanya kematian pada setiap makhluk Allah.

Mendoakan kepada orang yang masih hidup atau yang sudah mati dalam Islam sangat dianjurkan. demikian juga berzikir dan membaca Alquran juga sangat dianjurkan dalam Islam. Akan tetapi, jika di dalam berzikir dan membaca Alquran itu diniatkan untuk mengirim pahala kepada orang yang sudah mati, hal itu tidak berdasar pada ajaran agama, oleh karena itu harus ditinggalkan. Demikian juga tahlilan dan salawatan pada hari kematian ke-3, ke-7, ke-40, ke100, dan ke-1000 hari, hal itu merupakan bid'ah yang mesti ditinggalkan dari perbuatan Islam. Selain itu, masih banyak lagi hal-hal yang ingin diusahakan oleh Muhammadiyah dalam memurnikan tauhid ${ }^{4}$.

Sifat Tajdid yang dikenakan pada gerakan Muhammadiyah sebenarnya tidak hanya sebatas pengertian upaya memurnikan ajaran Islam dari berbagai kotoran yang menempel pada tubuhnya, melainkan juga termasuk upaya Muhammadiyah melakukan berbagai pembaharuan cara-cara pelaksanaan Islam dalam kehidupan bermasyarakat, semacam memperbaharui cara penyelenggaraan pendidikan, cara penyantunan terhadap fakir miskin dan anak yatim, cara pengelolaan zakat fitrah dan zakat harta benda, cara pengelolaan rumah sakit, pelaksanaan sholat Id dan pelaksanaan kurban dan sebagainya.

Untuk membedakan antara keduanya maka tajdid dalam pengertian pemurnian dapat disebut purifikasi (purification) dan tajdid dalam pembaharuan dapat disebut reformasi (reformation). Dalam hubungan dengan salah satu ciri Muhammadiyah sebagai gerakan tajdid, maka Muhammadiyah dapat dinyatakan sebagai Gerakan Purifikasi dan Gerakan Reformasi ${ }^{5}$.

4jsnurul.wordpress.com. Diakses 7 Juli 2012 pukul 11.49 wib.

5 www.muhammadiyah.or.id, diakses 7 Juni 2012 pukul 11.49 wib. 


\section{KESIMPULAN}

Sebagai gerakan dakwah, Muhammadiyah tidak hanya menyadarkan umat dari aspek personal tetapi juga membangun kesadaran tauhid sosial sebagai basis dan komitmen dakwahnya. Di dalam perjalanannya upaya untuk mengimplementasikan atau membumikan tauhid sosial didukung oleh empat doktrin lainnya yang juga hidup di kalangan warga Muhammadiyah. Empat doktrin tersebut adalah doktrin pencerahan umat, doktrin menggembirakan amal salih, doktrin kerjasama untuk kebajikan, doktrin tidak berpolitik praktis.

Dakwah Muhammadiyah tidak semata persoalan spiritual, tetapi juga sosial. Dakwah tidak dipahami sebagai tabligh, tetapi gerakan massif pada berbagai aspek kehidupan manusia. Muhammadiyah menyeimbangkan dakwah yang sifatnya spiritualitas dengan amal sosial sebgaai gerakan nyata sebagai jawaban atas problem umat di berbagai levelnya. Ciri-ciri perjuangan dalam dakwah Muhammdiyah itu adalah muhammadiyah sebagai gerakan islam, muhammadiyah adalah gerakan dakwah islam amar ma'ruf nahi munkar, muhammadiyah adalah gerakan tajdid.

\section{DAFTAR PUSTAKA}

Abdullah, M. Amin. 1995. Intelektualisme Muhammadiyah: Menyongsong Era Baru (Pendekatan "Teologis" Dalam Memahami Muhammadiyah. Bandung: Mizan

Muhtadi, Asep S. 2012. Meretas Jalan Dakwah: Benang Merah Gerakan Ormas Islam (Dakwah dan Gerakan Pembaruan Muhammadiyah). Bandung: MUI Kota Bandung.

Sya'bi, Akhmad. 1997. Kamus An-Nur. Surabaya : Halim.

Tabroni, Roni. 2012. Meretas Jalan Dakwah: Benang Merah Gerakan Ormas Islam (Revitalisasi Gerakan Dakwah Muhammadiyah). Bandung: MUI Kota Bandung. 
jsnurul.wordpress.com.

www.muhammadiyah.or.id 